\title{
Possible Involvement of Glutamatergic, Adrenergic and Dopaminergic System in Methylphenidate - induced Motor Activity and Mood-related Alterations in Rats
}

\author{
Kowsar Jahanbakshi $^{1}$ (D), Sulail Fatima ${ }^{2}$ (D), Majid Motaghinejad ${ }^{1,3 *(D)}$, Manijeh Motevalian ${ }^{1(D)}$
}

1. Dept. of Medicine, Qom Branch, Islamic Azad University, Qom, Iran.

2. Dept. of Physiology, Jinnah Medical \& Dental College, Sohail University, Karachi, Pakistan

3. Razi Drug Research Center, Iran University of Medical Sciences, Tehran, Iran

\begin{tabular}{|c|c|}
\hline Article Info & ABSTRACT \\
\hline doi $10.30699 / j a m b s .29 .137 .309$ & \multirow{2}{*}{$\begin{array}{l}\text { Background \& Objective: Methylphenidate (MPH), as a central nervous system } \\
\text { stimulant, is often used to manage hyperactive disorders. The literature is scarce } \\
\text { regarding the behavioral consequences of chronic MPH treatment and the role of } \\
\text { involved receptors. Thus, in the current study involved receptors in MPH induced- } \\
\text { anxiety, depression and motor activity disorders were evaluated. }\end{array}$} \\
\hline $\begin{array}{c}\text { Received: 2020/01/15; } \\
\text { Accepted: 2021/02/21; } \\
\text { Published Online: 01 Aug 2021; }\end{array}$ & \\
\hline $\begin{array}{l}\text { Use your device to scan and read the } \\
\text { article online }\end{array}$ & $\begin{array}{l}\text { Materials \& Methods: Seventy rats were randomly distributed to seven groups ( } \mathrm{n}= \\
10 \text {, per group); they were treated with normal saline, Domoic acid (DOM) (as } \\
\text { AMPA/kainite receptor agonist), Bicuculline (BIC) (as GABA receptor antagonist) }\end{array}$ \\
\hline 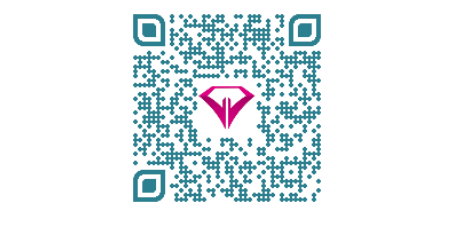 & $\begin{array}{l}\text { Ketamine (KET) (as NMDA receptor antagonist ), Yohimbine (YOH) (as Alpha-2 } \\
\text { adrenergic receptor antagonist), or Haloperidole (HAL) (as } \mathrm{D}_{2} \text { dopamine receptor } \\
\text { antagonist), simultaneously with MPH ( } 10 \mathrm{mg} / \mathrm{kg} \text { ). On days } 11,17 \text { and } 24 \text {, some } \\
\text { standard behavior tests including Elevated Plus Maze (EPM), Forced Swim Test } \\
\text { (FST) and Open Field Test (OFT) were used to investigate anxiety, depression and } \\
\text { motor activity disturbances, respectively. }\end{array}$ \\
\hline $\begin{array}{l}\text { Corresponding Information: } \\
\text { Majid Motaghinejad, }\end{array}$ & $\begin{array}{l}\text { Results: Our study indicated that pretreatment of rats with KET, HAL and YOH } \\
\text { abolished MPH induced - mood and motor activity disturbances. }\end{array}$ \\
\hline $\begin{array}{l}\text { Razi Drug Research Center, Iran Uni- } \\
\text { versity of Medical Sciences, Tehran, } \\
\text { Iran }\end{array}$ & $\begin{array}{l}\text { Conclusion: MPH by interacting with Dopaminergic, NMDA and } a_{2} \text {-adrenergic } \\
\text { receptors induces anxiety, depression and motor activity disorders. }\end{array}$ \\
\hline $\begin{array}{l}\text { E-Mail: } \\
\text { Dr.motaghinejad6@gmail.com }\end{array}$ & Keywords: Methylphenidate, Aanxiety, Depression and Motor activity \\
\hline (c) $($ i) $(9)$ & $\begin{array}{l}\text { of the Creative C } \\
\text { itation. }\end{array}$ \\
\hline
\end{tabular}

\section{Introduction}

Methylphenidate (MPH) as central stimulant agent is often used to treat and manage Hyperactive disorders [1]. Abuse or chronic consumption of MPH can cause mood changes such as cognitive impairments [1, 2]. By blocking some neurotransmitter transporters, MPH inhibits the presynaptic reuptake of dopamine, serotonin and norepinephrine, and allows potent stimulation of their respective receptors at post-synaptic end [3].

MPH is structurally similar to amphetamine, although it has less potent and takes much longer time for its action. Moreover, similar to cocaine, it has addictive properties, and therefore it is easily abused [2, 4-6]. Some undesirable effects of this stimulant can be seen during long term therapy, but still the scientific papers are scarce about consequences of MPH long term use [7]. Behavioral alterations following the chronic use of $\mathrm{MPH}$, include increased mood disturbances along with a significant decline in cognitive functions, inclusive of learning and memory [8]. Numerous studies have reported that long term administration of MPH and other amphetamine-like agents can cause neurodegeneration in some brain regions, such as hippocampus and amygdale, thereby affecting brain development and functions $[9,10]$.

MPH exerts its properties via norepinephrine and dopamine receptors, but its precise mechanism is not completely understood. Moreover, although some studies have demonstrated that MPH may induce long term changes in adult GABAergic system of prefrontal, but the exact mechanism and also the involvement of other receptors have remained unclear [11]. Glutamate system also appears to be involved in $\mathrm{MPH}$ - induced enhanced cognition and psychosis, which are frequently observed at low and high-doses of MPH, respectively [12]. Furthermore, the precise role of various neurotransmitter receptors in mediating behavioral effects of MPH is also unclear. Results based on previous data have illustrated, that $\mathrm{D}_{2}, \mathrm{GABA}_{\mathrm{A}}, \mathrm{NMDA}, \mathrm{AMPA}$ and Alpha 2 receptors 
play critical role in anxiety, depression and motor activity disturbances [12-18].

According to the previous reports, MPH can alter brain amines and their receptor function; it possibly exerts its effects via modulating these receptor systems. Keeping in view MPH - induced motor activity disturbance and mood changes, the current study was designed to explore the potential role of $\mathrm{D}_{2}, \mathrm{GABA}_{\mathrm{A}}$, NMDA, AMPA and Alpha 2 receptors in modulating these long term mood and motor activity - related disturbances in rats. The current study gives us insight about the role of neurotransmitter different receptors in mood - related effects induction of $\mathrm{MPH}$.

\section{Materials and Methods}

\section{Animals}

Seventy adult male rats weighing 180-220 gr and nine weeks aged were acquired from the rodent husbandry of Iran University of Medical Sciences (Tehran, Iran). All animals were transferred to the pharmacology department laboratory. Before starting the experiments, the animals were acclimatized to the new environment for 14 days. The animals were maintained at room temperature (22 \pm $2{ }^{\circ} \mathrm{C}$ ), and $12 \mathrm{~h}$ light and dark cycle. The rats were fed with standard food and tap water. All possible efforts were put in, to minimize the animal suffering during the experiment. All procedures were confirmed and approved by the research committee at the college of medicine, Islamic Azad University, Qom Branches (Research ethical code is: IR.IAU.QOM.REC.1399.007). The animal experiments were performed according to the guidelines for the care and use of mammals in neuroscience and behavioral researches (National Research Council, 2003) [19]. The ethical aspects of the study were affirmed by the Institutional Animal Ethical Committee.

\section{Drug}

MPH (Catalog number:M2892), Domoic Acid (DOM) (Catalog number:D6152) and Bicuculline (BIC) (Catalog number:14340 ) were obtained from Sigma-Aldrich (USA). Ketamine (KET) was purchased as ready to use vial from ROTEXMEDICA pharmaceuticals (Germany). Halperidole (HAL) (Batch number: 1425) and Yohimbine (YOH) (Batch number: 2012) were obtained from Iran Daru Pharmaceuticals company (Iran). All mentioned drugs were used as API (Active Pharmaceutical Ingredient), which is the standard form of the drug, to use in the experimental studies.

\section{Experimental design}

Seventy animals were randomly divided into seven groups ( $\mathrm{n}=10$, per group) as follow:

- Control group which treated by normal saline (0.7 $\mathrm{ml} / \mathrm{rat}$, i.p.) for 24 days.

- $\quad \mathrm{MPH}(10 \mathrm{mg} / \mathrm{kg}$, i.p.) treated group for 24 days.

- $\quad$ DOM (400 $\mu \mathrm{g} / \mathrm{kg}$, i.p.) and MPH (10 mg/kg, i.p.) treated group for 24 days.
- $\quad$ BIC (4 mg/kg, i.p.) and MPH (10 mg/kg, i.p.) treated group for 24 days.

- $\quad$ KET (10 mg/kg, i.p.) and MPH (10mg/kg, i.p.) treated group for 24 days.

- $\quad$ YOH (10 mg/kg i.p.) and MPH (10 mg/kg, i.p.) treated group for 24 days.

- $\quad$ HAL (10 mg/kg i.p.) and MPH (10 mg/kg, i.p.) treated group for 24 days.

In the groups receiving receptor antagonist and $\mathrm{MPH}$, there was a gap period of $45 \mathrm{~min}$ between the administrations of both agents. The antagonist was injected first, followed by the administration of MPH.

In the behavioral studies 8-12 animals are commonly employed (slightly more than usually used in experimental studies). This number yields smaller standard deviation and keeps the data normally distributed. The reason for using a higher number of animals in behavioral studies is that animals tend to behave differently and diversely, thereby affecting the overall dimension of the results. Therefore, as commonly used by other studies, we used 10 rates for each group (total: 70). However, it could be more accurate if we had precisely determined the sample size.

It should be noted that all animals received mentioned agents for 24 days. Considering the $3 \mathrm{R}$ principles of human experimentation for animals (replacement, reduction and refinement), we used the same animals for performing three behavioral tests. The experiments were designed in such a manner to induce minimal anxiety in the experimental animals. We performed the tests on days 11 , 17 and 24, and each test had a 3-hour rest interval. In the morning, we performed the Open Field Test (OFT) as the first one, followed by a 3-hour rest period. Next, we performed Elevated Plus Maze (EPM) and finally, after 3 hours Forced Swim Test (FST) was performed. In this way, anxiety hardly interfered with the test results. Also as mentioned, the presence of 10 animals in each group prevents the occurrence of heterogeneous data and reduces diversity and large standard deviation.

\section{Behavior Tests Open Field Test (OFT)}

This behavioral test was performed to assess locomotor activity, anxiety and exploratory behavior in treated animals. Animal behavioral analysis was done based on the previous standard studies, employing OFT protocol [20]; the behavior characteristics including: ambulation distance, frequency of rearing, time spent in center square and frequency of central square entries were also recorded [20].

\section{Forced Swim Test (FST)}

This test was used to assess depression - like behaviors in rats. Immobility and swimming activity were recorded in FST. Animal behavioral analysis was done based on the previous standard works [21]. 


\section{Elevated Plus Maze (EPM)}

This assay was performed to evaluate the pattern of anxiety experimental animals. It was done according to the previously published literature [22]. The time spent in the open and closed arms was recorded for each rat. Moreover, the number of entries into each type of arm was also recorded. More frequent entry and longer duration of stay in open arm were the indicative of lower levels of stress and anxiety.

\section{Statistical analysis}

The data were investigated and analyzed using GraphPad PRISM v.6 software (2016) (Graph Pad Company, San Diego, USA). First, the normality of continuous variables (behavioral parameters) was assessed using Kolmogorov-Smirnov test. All data were indicated as means \pm standard error. Since the variables were measured and repeated in different days, the difference between the treatment groups was evaluated using oneway ANOVA repeated measures, followed by a multiple comparison test using Tukey-Kramer test; results were considered to be statistically significant at $p<0.05$ level.

\section{Results}

\section{OFT results}

On days 11, 17 and 24, the animals receiving MPH traversed less ambulatory distance. The rearing behavior decreased in the cited animals in comparison to the control group $(\mathrm{P}<0.05)$ (Figure-1A and $\underline{\mathrm{B}})$. Also, the control group had more frequency of central square entrance; they showed increase in time spent in central region of the OFT, as compared to the MPH alone treated group (P$<0.05$ ) (Figure-1C and D). Pretreatment of animals with KET, HAL and YOH improved ambulation distance, time spent in the central square and number of entries to central squares in OFT in all days of test $(\mathrm{P}<0.05)$ (Figure-1 A D).

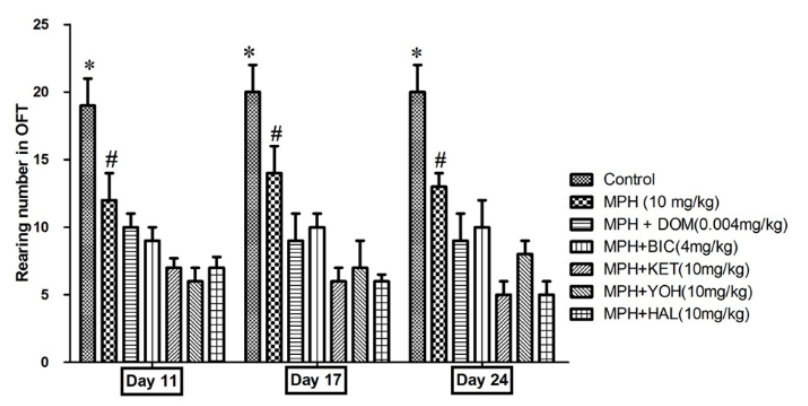

B

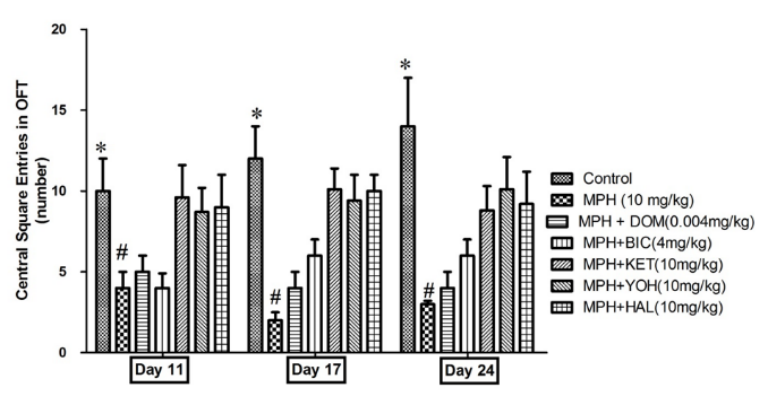

C

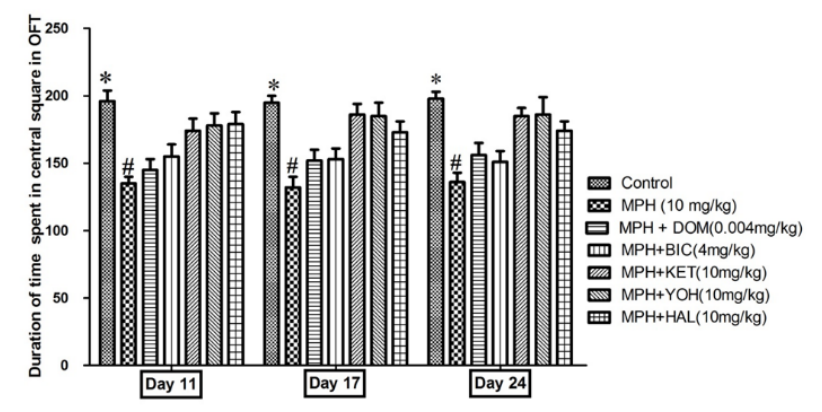

D

Figure 1. Effect of DOM, BIC, KET, YOH or HAL on MPH-induced alterations in OFT behaviors, such as: ambulation distance (A), rearing number(B), central square entries(C), duration of time spent in central square(D). All data are presented as Mean \pm SEM $(\mathrm{N}=8)$.

$* \mathrm{P}<0.05$ vs. MPH treated group

\# $\mathbf{P}<0.05$ vs. KET, HAL, YOH

MPH: methylphenidate, BIC: Bicuculline, DOM: Domoic acid, YOH :Yohimbine, KET: Ketamine, HAL: Haloperidole

\section{FST results}

As shown in figure 2, the animals in the control group compared to $\mathrm{MPH} 10 \mathrm{mg} / \mathrm{kg}$ treated rats, spent more swimming time in the FST, and less time being immobile on days 17 and $24(\mathrm{P}<0.05)$ (Figure-2A and $\underline{B})$. KET, $\mathrm{HAL}$, and $\mathrm{YOH}$ abolished the behavioral disturbances, like reduction the swimming time and increase the immobility time, when were assessed on days 17 and 24 in the MPH addicted animal $(\mathrm{P}<0.05)$ (Figure-2 A and $\underline{B})$.

\section{EPM results}

As indicated in figure-3, MPH treated animals showed reduction in the time spend in open arm and frequency of entries into open arm of EPM on day 11, 17 and 24, comparison to the control animals $(\mathrm{P}<0.05)$ (Figure-3A 


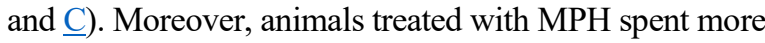
time in closed arm, and entered closed arm in comparison to the animals in control group, when assessed on days 17 and 24 of the experiment $(\mathrm{P}<0.05)$ (Figure-3B and $\underline{\mathrm{D}})$. Treatment of animals with KET and $\mathrm{YOH}$ suppressed MPH-induced behavioral disturbances; it attenuated time spent in open arm and number of entries into open arm. Finally, it caused escalation in the time spent in closed arm and increased the number of entries into closed arm, when compared to MPH treated group on day 11,17 and 24 $(\mathrm{P}<0.05)$ (Figure-3A, $\underline{\mathrm{B}}, \underline{\mathrm{C}}$ and $\underline{\mathrm{D}})$

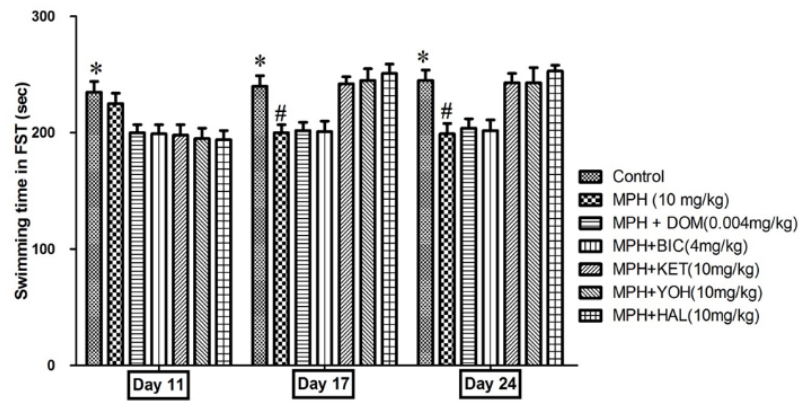

$\mathbf{A}$

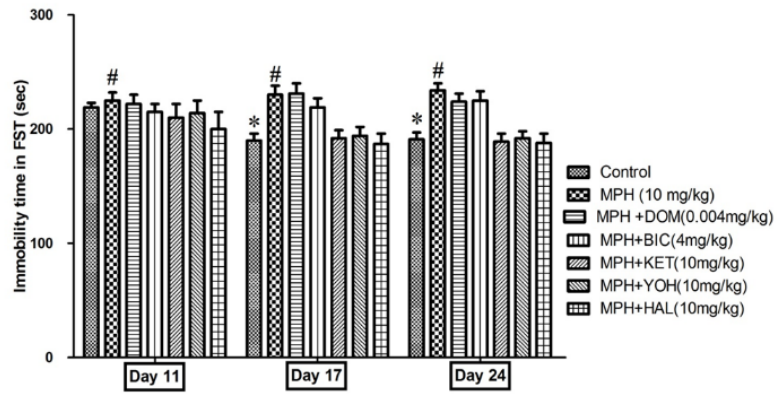

B

Figure 2. Effect of DOM, BIC, KET, YOH or HAL on MPH-induced alterations in FST behaviors, such as: Swimming time (A) and immobility time (B). All data are presented as Mean $\pm \operatorname{SEM}(\mathrm{N}=8)$.

$* P<0.05$ vs. MPH treated group

\# $\mathbf{P}<0.05$ vs. KET, HAL, YOH

MPH: methylphenidate, BIC: Bicuculline, DOM: Domoic acid, YOH :Yohimbine, KET: Ketamine, HAL: Haloperidole

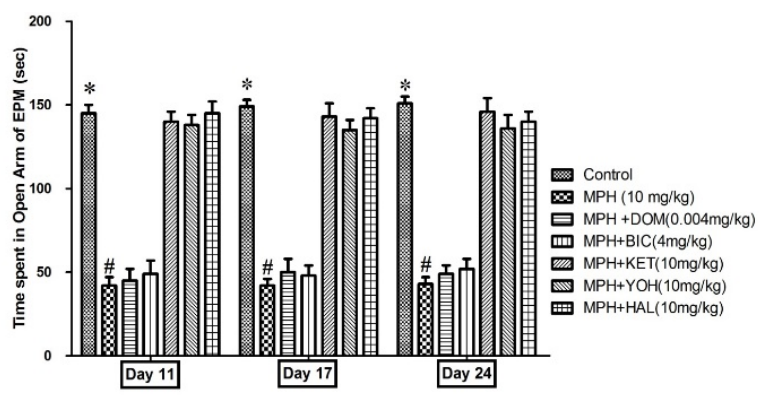

A

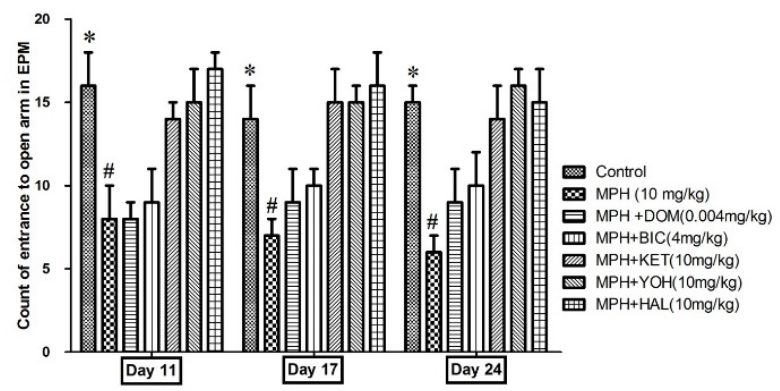

C

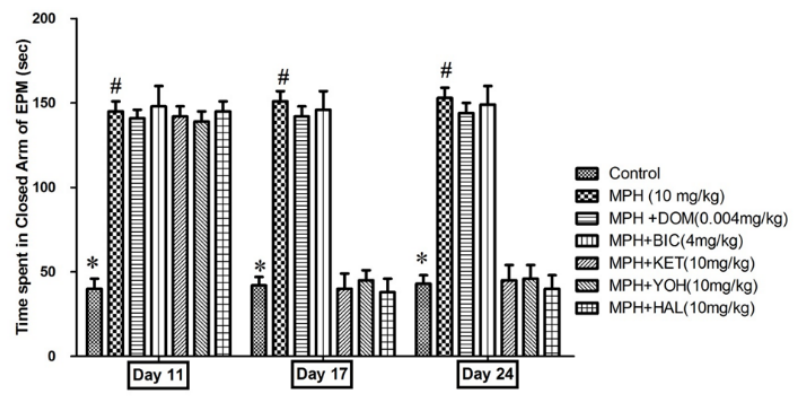

B

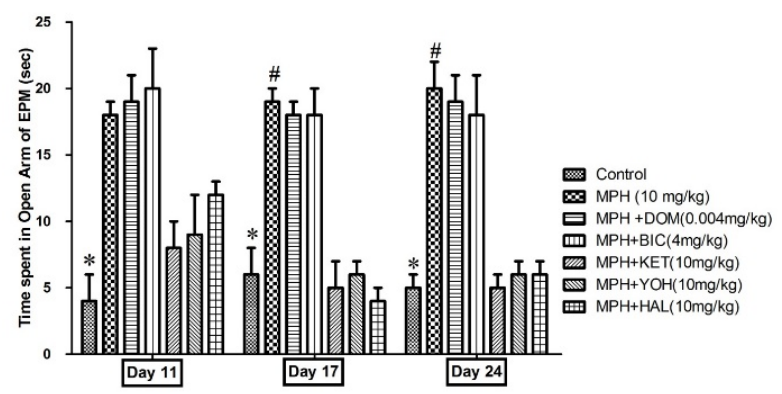

D

Figure 3. Effect of DOM, BIC, KET, YOH or HAL on EPM behaviors, such as: time spent in open arm (A), time spent in closed $\operatorname{arm}(B)$, count of entrance to open $\operatorname{arm}(\mathrm{C})$ and count of entrance to closed $\operatorname{arm}(\mathrm{D})$. All data are presented as Mean \pm SEM (N=8).

$* \mathbf{P}<0.05$ vs. MPH treated group

\# $\mathbf{P}<0.05$ vs. KET, HAL, YOH

MPH: methylphenidate, BIC: Bicuculline, DOM: Domoic acid, YOH :Yohimbine, KET: Ketamine, HAL: Haloperidole

\section{Discussion}

This study indicated that 24 days' administration of MPH induces motor activity and mood - related disturbances in rodents. Our data showed that NMDA, alpha adrenergic and dopaminergic receptors appear to mediate MPH - induced behavioral effects. We found that treatment of rats with KET, HAL and $\mathrm{YOH}$ can 
diminish MPH - induced motor activity and mood disturbances in OFT and EPM, when assessed on days 11,17 and 24. Also, pretreatment with KET, HAL and YOH can abolish MPH - mediated depression - like behavior in FST, when assessed on days 17 and 24 .

MPH is as neural stimulant agent, that is used for treatment of hyperactive children with attention deficit disorder [23]. This agent acts like methamphetamine compounds such as Methylenedioxymethamphetamine (MDMA) [24]. It binds to dopamine and also norepinephrine transporter, thus inhibits their reuptake to the presynaptic terminals $[24,25]$.

During recent years, MPH abuse has increased; it necessitates further researches on the exact action mechanism of this drug [26]. Although according to basic pharmacological research, it has been demonstrated that MPH acts by limiting the reuptake of mentioned neurotransmitter into the presynaptic terminals [3]. The clear role of some strategic receptors of this amine and other related neurotransmitter receptors remain unclear $[3,27]$. It has been indicated that $\mathrm{MPH}$ may induce chronic effects in GABAergic system of brain cells, but the involvement of receptors remains unclear [11]. Other similar studies have evaluated the potential role of glutamate system in cognitive improvement effects of low-dose MPH, as well as the induction of psychosis at high-dose of MPH [12, 28].

Although, the role of MPH is clarified in modulating some neurotransmitters such as: norepinephrine, dopamine, GABA and glutamate, but the exact role of their important receptors such as: $\mathrm{D}_{2}$ receptor of dopamine, NMDA and AMPA receptor of ketamine, $\mathrm{GABA}_{\mathrm{A}}$ receptor of GABA and Alpha 2 receptor of norepinephrine remains unclear; they are important in mood and motor activity related behaviors [12-18], and modulation of MPH neurobehavioral effects.

The current literature has limited data, regarding the role of different receptors in mediating the neurobehavioral changes caused by MPH abuse. Here, we concurrently treated rats with high doses of $\mathrm{MPH}$ and receptor agonists/antagonists agents such as: DOM, $\mathrm{BIC}$, KET, YOH and HAL, as strategic receptors antagonist. We found that treated animals with HAL, KET and YOH can attenuate MPH - induced behavioral changes. In particular, treatment of animals with $\mathrm{HAL}, \mathrm{KET}$ and $\mathrm{YOH}$ reversed $\mathrm{MPH}$ - induced changes in OFT.

According to the recent studies, MPH - induced anxiety and stimulatory effects are mediated via activation of glutamatergic receptor or inhibition of Alpha-2 and $\mathrm{D}_{2}$ receptor of, respectively [29-32]. In consistent with our results, a previous work has demonstrated that reduction in the number of NMDA receptors can modulate anxiety and motor activity- like behaviors [33]. Moreover, it has been shown that activation of $\mathrm{GABA}_{\mathrm{A}}$ and NMDA receptors can affect mood related behaviors; the role of $\mathrm{D}_{2}$ and Alpha-2 receptors is less explored [34]. Here, we found that chronic administration of $\mathrm{MPH}$, via modulating $\mathrm{D}_{2}$, NMDA and Alpha-2 receptors can reverse motor activity and mood related behavioral dysfunctions in OFT, when is tested on days 11, 17 and 24 of the study [34].

Thus, it can be suggested that inhibition of receptors such as NMDA, Alpha 2 and $\mathrm{D}_{2}$ can abolish the MPHinduced behavioral changes. Many previous studies have shown that high activation of NMDA receptors induces anxiety and depression and also modulates motor activity changes [35]. It was shown that activation of Alpha- 2 and $\mathrm{D}_{2}$ receptors is involved in antidepressant and anxiolytic properties of some new sedative agents [13, 36]. Several studies have also shown that activation of $\mathrm{D}_{2}, \mathrm{NMDA}$ or $\mathrm{a}_{2}$-adrenergic receptors is responsible for the neurochemical effects of MPH, but the role of these receptor systems in causing MPH - induced mood related behavioral changes remains unclear [13-15]. Current study demonstrated that treatment of animals with KET, HAL and YOH reversed MPH - induced decrease in swimming time and increase the immobility time in FST, during the days 17 and 24 in the MPH treated animals. It also suggests, that MPH triggers motor activity disturbances and anxiety- like behaviors in FST, via activation NMDA, $\mathrm{D}_{2}$ and Alpha-2 receptors.

Our data indicated that HAL, KET and $\mathrm{YOH}$ administration reduces MPH-induced depressive - like behaviors. As mentioned above many studies have shown that MPH can promote depression in brain by interacting with $\mathrm{D}_{2}$, NMDA and Alpha-2 receptors [1216]. Previous studies have expressed that various dosage regimen of MPH administration can activate signaling pathway for depression [37, 38]. It was demonstrated that normal physiological activity of D2, NMDA and Alpha-2 receptor can stimulate brain functioning against depression [12-18]. These data also demonstrated that increased activation or even increased inhibition of this receptor can induce depression [12-18].

According to the current study, MPH could promote depression - like behaviors in FST, by modulating $\mathrm{D}_{2}$, NMDA and Alpha-2 receptors. In addition, blockade of these receptors can suppress MPH - induced depression - like behaviors in FST.

Current study suggested that $\mathrm{D}_{2}$, NMDA and Alpha2 receptors are involved in depressive effect of MPH. Treatment with DOM, KET and YOH led to increase the time spent in open arm and entrance count to open arm, and also decreased time spent in closed arm and count of entrance to closed arm in EPM, on days 11, 17 and 24 in the MPH addicted rats; it has been confirmed by previous studies [12-18]. It was demonstrated that high activation of $\mathrm{D}_{2}$, NMDA and Alpha- 2 receptors can modulate anxiety pathways, and there are multiple mechanisms for this effect [12-16]. In essence, the current study showed that MPH by activation of $\mathrm{D}_{2}$, NMDA and Alpha-2 receptor can cause anxiety; blockade of these receptors can also suppress anxiety associated with MPH abuse. Our results confirmed the 
effects of these receptors on behavioral changes of MPH administration.

\section{Conclusion}

The present study suggested the effects of chronic MPH administration at high doses, on motor activity and mood - related changes. Furthermore, our findings suggested the importance of NMDA, $\mathrm{D}_{2}$ and Alpha-2 receptors in mediating these behavioral malicious effects. The data indicated that long term administration of $\mathrm{MPH}$, via modulating Alpha-2, $\mathrm{D}_{2}$ and NMDA receptors can reverse anxiety and depression like behaviors and motor activity disturbances, as observed in OFT, EPM (during days 11, 17 and 24) and FST (during days 17 and 24).

\section{Acknowledgments}

None.

\section{Conflict of Interest}

None.

\section{References}

1. Klein-Schwartz W. Abuse and toxicity of methylphenidate. Curr Opinion Pediatr. 2002. 14(2): 219-23. [DOI:10.1097/00008480200204000-00013]

2. Yano $M$, Steiner $H$. Methylphenidate and cocaine: the same effects on gene regulation? Trend Pharmacol Sci. 2007; 28(11): 588-96. [DOI:10.1016/j.tips.2007.10.004]

3. Scahill L, Carroll D, Burke K. Methylphenidate: mechanism of action and clinical update. J Child Adolescent Psychiatr Nur. 2004; 17(2): 85-86. [DOI:10.1111/j.1744-6171.2004.00085.x]

4. Logan B. Methamphetamine-effects on human performance and behavior. Forensic Sci Rev, 2002. 14(1): 133-51.

5. Kim Y, Teylan M, Baron M, Sands A, Nairn A, Greengard P .Methylphenidate-induced dendritic spine formation and $\triangle \mathrm{FosB}$ expression in nucleus accumbens. Proc Natl Acad Sci. 2009. 106(8): 2915-20. [DOI:10.1073/pnas.0813179106]

6. Klein-Schwartz W, McGRATH J. Poison centers' experience with methylphenidate abuse in preteens and adolescents. J Am Acad Child Adoles Psychiatr. 2003. 42(3): 288-94. [DOI:10.1097/00004583-200303000-00008]

7. Carlezon Jr, Mague W, Andersen SL. Enduring behavioral effects of early exposure to methylphenidate in rats. Biol Psychiatr.
2003;54(12):

1330-37

[DOI:10.1016/j.biopsych.2003.08.020]

8. Vendruscolo L, Izídio G, Takahashi R, Ramos A .Chronic methylphenidate treatment during adolescence increases anxiety-related behaviors and ethanol drinking in adult spontaneously hypertensive rats. Behav Pharmacol. 2008; 19(1): 21-27. [DOI:10.1097/FBP.0b013e3282f3cfbe]

9. Riddle EL, Fleckenstein AE, Hanson GR. Mechanisms of methamphetamine-induced dopaminergic neurotoxicity. AAPS J. 2006; 8(2): E413-E418. [DOI:10.1007/BF02854914]

10. Martins M, Reinke A, Petronilho F, Gomes K, Dal-Pizzol F, Quevedo J.Methylphenidate treatment induces oxidative stress in young rat brain. Brain Res. 2006. 1078(1): 189-97. [DOI:10.1016/i.brainres.2006.01.004]

11. Solleveld M, Schrantee A, Puts N, Reneman L, Lucassen P.Age-dependent, lasting effects of methylphenidate on the GABAergic system of ADHD patients. NeuroImage. 2017 15: 812-18. [DOI:10.1016/j.nicl.2017.06.003]

12. Jia Cheng, Zhe Xiong, Lara J Duffney, et al. Methylphenidate exerts dose-dependent effects on glutamate receptors and behaviors. Biol Psychiatry. 2014. 76(12): 953-62. [DOI:10.1016/j.biopsych.2014.04.003]

13. Haenisch B, Bönisch H. Depression and antidepressants: insights from knockout of dopamine, serotonin or noradrenaline re-uptake transporters. Pharmacol Therap. 2011; 129(3): 352-68.

[DOI:10.1016/j.pharmthera.2010.12.002]

14. Gronier B. In vivo electrophysiological effects of methylphenidate in the prefrontal cortex: involvement of dopamine D1 and alpha 2 adrenergic receptors. Europ Neuropsychopharmacol. 2011. 21(2): 192-204. [DOI:10.1016/j.euroneuro.2010.11.002]

15. Rozas C. Methylphenidate amplifies long-term potentiation in rat hippocampus CA1 area involving the insertion of AMPA receptors by activation of $\beta$-adrenergic and D1/D5 receptors. Neuropharmacol. 2015. 99: p. 15-27. [DOI:10.1016/j.neuropharm.2015.07.003]

16. Furini C, Behling J, Zinn C, Zanini M.Extinction memory is facilitated by methylphenidate and regulated by dopamine and noradrenaline receptors. Behav Brain Res. 2017. 326: 303-6. [DOI:10.1016/j.bbr.2017.03.027]

17. Gamo N, Wang M, Arnsten A. Methylphenidate and atomoxetine enhance prefrontal function through $\alpha 2$-adrenergic and dopamine D1 receptors. J Am Acad Child Adoles Psychiatr. $2010 . \quad$ 49(10): 1011-23. [DOI:10.1016/j.jaac.2010.06.015] 
18. Gill KE, Beveridge T, Smith HR, Porrino LJ.The effects of rearing environment and chronic methylphenidate administration on behavior and dopamine receptors in adolescent rats. Brain Res. 2013; 1527: 67-78. [DOI:10.1016/i.brainres.2013.06.021]

19. Staff N. Guidelines for the care and use of mammals in neuroscience and behavioral research. 2003: National Academies Press.

20. Gould T, Dao D, Kovacsics C. The open field test, in Mood and anxiety related phenotypes in mice. 2009, Springer. 1-20. [DOI:10.1007/978-160761-303-9 1]

21. Can A, Dao DT, Arad M, Terrillion CE, Piantadosi SC, Gould TD.The mouse forced swim test. J Visual Experiment. 2012(59): e3638. [DOI:10.3791/3638]

22. Komada M, Takao K, Miyakawa T. Elevated plus maze for mice. J Visual Experiment, 2008(22): e1088. [DOI:10.3791/1088]

23. Challman TD, Lipsky J. Methylphenidate: its pharmacology and uses. in Mayo Clinic Proceedings. $2000 . \quad$ Elsevier. [DOI:10.4065/75.7.711]

24. Tagaya H. Methylphenidate: pharmacology, indication and potential of abuse. Nihon rinsho. Japan J Clin Med, 2010. 68(8): 1550-55.

25. Huss M, Lehmkuhl U. Methylphenidate and substance abuse: a review of pharmacology, animal, and clinical studies. J Attention Disorders. 2001. 6: S65-71. [DOI:10.1177/070674370200601S09]

26. Iliou T, Casta P, Lequeux J, Pochard L, Frauger E, Spadari M, Micallef J.Venlafaxine Abuse in a Patient With a History of Methylphenidate Abuse: A Case Report. J Clin Psychopharmacol. 2019. 39(2): $172-7$

[DOI:10.1097/JCP.0000000000001011]

27. Stevens T, Sangkuhl K, Brown JT, Altman RB, Klein TE.PharmGKB summary: methylphenidate pathway, pharmacokinetics/pharmacodynamics. Pharmacogenetics Genomics. 2019. 29(6): 13654. [DOI:10.1097/FPC.0000000000000376]

28. Miller EM, Quintero JE, Pomerleau F, Huettl P, Gerhardt GA, Glaser PE.Chronic methylphenidate alters tonic and phasic glutamate signaling in the frontal cortex of a freely-moving rat model of ADHD. Neurochem Res. 2019. 44(1): 89-101 [DOI:10.1007/s11064-018-24831]

29. Bartl J, Link P, Schlosser C, et al. Effects of methylphenidate: the cellular point of view. ADHD Attention Deficitand Hyperactivity Disorders. 2010. 2(4): 225-32. [DOI:10.1007/s12402-010-0039-6]
30. Koda K, Ago Y, Cong Y, Kita Y, Takuma K, Matsuda T.Effects of acute and chronic administrationof atomoxetine and methylphenidate on extracellular levels of noradrenaline, dopamine and serotonin in the prefrontal cortex and striatum of mice. J Neurochem. 2010. 114(1): 259-70. [DOI:10.1111/j.1471-4159.2010.06750.x]

31. Levin ED, Sledge D, Roach S, Petro A, Donerly S, Linney E.Persistent behavioral impairment caused by embryonic methylphenidate exposure in zebrafish. Neurotoxicol Teratol. 2011. 33(6):p. 668-673. [DOI:10.1016/j.ntt.2011.06.004]

32. Motaghinejad M, Motevalian M. Involvement of AMPA/kainate and GABAA receptors in topiramate neuroprotective effects against methylphenidate abuse sequels involving oxidative stress and inflammation in rat isolated hippocampus. Eur J Pharmacol. 2016. 784: 18191. [DOI:10.1016/j.ejphar.2016.04.036]

33. Zhang CL, Feng ZJ, Liu Y,et al.Methylphenidate enhances NMDA-receptor response in medial prefrontal cortex via sigma-1 receptor: a novel mechanism for methylphenidate action. PloS one, 2012. 7(12): p. e51910. [DOI:10.1371/journal.pone.0051910]

34. Motaghinejad M, Motevalian M, Fatima S. Mediatory role of NMDA, AMPA/kainate, GABAA and Alpha2 receptors in topiramate neuroprotective effects against methylphenidate induced neurotoxicity in rat. Life Sci. 2017. 179: 37-53. [DOI:10.1016/j.1fs.2017.01.002]

35. Barkus C, McHugh SB, Sprengel R, Seeburg PH, Rawlins JN, Bannerman DM.Hippocampal NMA receptors and anxiety: at the interface between cognition and emotion. Europ J Pharmacol. 2010. 626(1):

49-56. [DOI:10.1016/j.ejphar.2009.10.014]

36. Racagni G, Popoli M. The pharmacological properties of antidepressants. Int Clin Psychopharmacol. 2010. 25(3): 117-31. [DOI:10.1097/YIC.0b013e3283311acd]

37. Urban KR, Waterhouse BD, Gao WJ. Distinct age-dependent effects of methylphenidate on developing and adult prefrontal neurons. Biol $\begin{array}{lll}\text { Psychiatr. } 2012 . & 72(10): \quad 880-88 .\end{array}$ [DOI:10.1016/j.biopsych.2012.04.018]

38. Devos D, Moreau C, Delval A, Dujardin K, Defebvre L, Bordet R. Methylphenidate. CNS Drugs. 2013. 27(1): 1-14. [DOI:10.1007/s40263012-0017-y] 


\section{How to Cite This Article:}

Jahanbakshi K, Fatima S, Motaghinejad M, Motevalian M, Possible Involvement of Glutamatergic, Adrenergic and Dopaminergic System in Methylphenidate - induced Motor Activity and Mood-related Alterations in Rats, J Adv Med Biomed Res. 2021; 29(137): 309-316

\section{Download citation:}

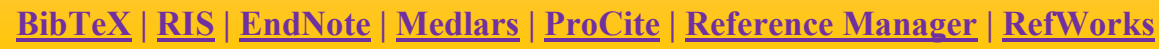

\section{Send citation to:}

8 Mendeley 2 Zotero RefWorks RefWorks 